\title{
Get me outta here! Motivating online learners with digital escape rooms
}

\author{
Lucy Gill-Simmen \\ Royal Holloway, University of London, UK
}

Keywords: motivation; online learning; digital escape rooms.

\section{The challenge}

In education, motivation has been identified as a key determinant of learning (Lim, 2004). It is used to explain the attention and effort students dedicate to particular learning activities (Brophy, 2013). Studies have shown that learner motivation has an impact on a number of key learning outcomes such as persistence (Vallerand and Bissonnette, 1992), retention (Lepper and Cordova, 1992), achievement (Eccles, 1983), and course satisfaction (Fujita-Starck and Thompson, 1994). Although motivation is critical in any learning environment, it is particularly so in an online environment (Mullen and TallentRunnels, 2006). Motivation is particularly important in online classes as students must work alone, have little face-to-face interaction with the instructor or peers, and frequently encounter ambiguous learning situations (Sankaran and Bui, 2001).

Following the introduction of a flexible learning model at a UK public research university, online learning became a necessity on an undergraduate Marketing Strategy course. With the exception of one hour of in-person teaching and a one hour synchronous online session, students were required to work their way independently through a series of learning activities provided on the virtual learning environment (VLE), Moodle. This presented me with the challenge of ensuring a class of 450 students would be motivated to engage and participate in the learning activities on the VLE to achieve the required learning outcomes for the course. The course was designed as a series of five two-week 'blocks' to run over the ten week semester. Each block covered a stage in the strategic planning process. Not only was it important for students to engage in all the learning 
materials for each block to ensure learning outcomes were met but also that they studied the blocks in chronological order to fully understand the strategic planning 'journey'. Besides course delivery, my role thus became to manage learner motivation. Specifically, the objective was to increase motivation levels with a view to engendering positive outcomes, such as increased effort, persistence, and enhanced performance (Buckley and Doyle, 2016).

Specifically, the challenge I needed to address was to design an activity for continuity, with an element of incentivisation, to motivate the student to the next stage.

\section{The response}

Gamification in education rose to popularity in the early 2010 s and may be defined as 'using game-based mechanics, aesthetics and game thinking to engage people, motivate action, promote learning, and solve problems' (Kapp, 2012, p.10).

There is evidence that games and gamification can positively influence intrinsic motivation by providing students with autonomy, relatedness and competence (Coller and Shernoff, 2009; Barata et al., 2013). There are a number of ways in which gamification can be incorporated into instructional design through quizzes, competitions, badges, and leader boards (Dichev and Dicheva, 2017).

The mode of gamification that I chose was a digital escape room. As I was seeking an activity that encouraged continuity, this approach seemed ideal, since by nature, an escape room incentivises the participant to progress from one room to another to fully escape. In addition, digital escape rooms not only facilitate an active learning environment but also encourage participation, maximize motivation, and enhance learning (Borrego et al., 2017). In particular, research has shown three outcomes of digital escape rooms that concern the affective domain: engagement, motivation, and satisfaction (Makri, Vlachopoulos and Martina, 2021).

I designed the digital escape room experience using Google Forms (you can also use OneNote). Five sections of the Google Form were used, each section serving as a 'room' 
(Figure 1.) Each room required knowledge and understanding of the corresponding teaching block to crack the codes required to escape.

In each of the five sections, four problems were presented for the student to solve (Appendix 1). Each correct answer served as a code to 'unlock' one lock in the room. The answer to the problem, puzzle, or clue was in the form of a word, a series of letters, or a number. Response validation was used to check the answer, and if it was correct, the student could move to the next 'lock' and eventually escape the room. If students entered an incorrect answer in the answer field, then a message was displayed saying 'incorrect'. The questions and puzzles were specifically designed around the learning activities in the block and the answers could not be found elsewhere. If students were struggling to crack the code, they were encouraged to email the instructor to ask for a clue.

From analysis of the metrics on Google Forms, $72 \%$ of students started the activity and $67 \%$ of the students managed to fully make their escape. The student evaluation for the course suggested students found the digital escape room 'fun' and 'enjoyable'. One student declared: 'I loved the escape room, it was really fun, I kept going to get to the final clue and was psyched when I got out!'

\section{Figure 1. Cover page marketing strategy digital escape room in Google Forms.}

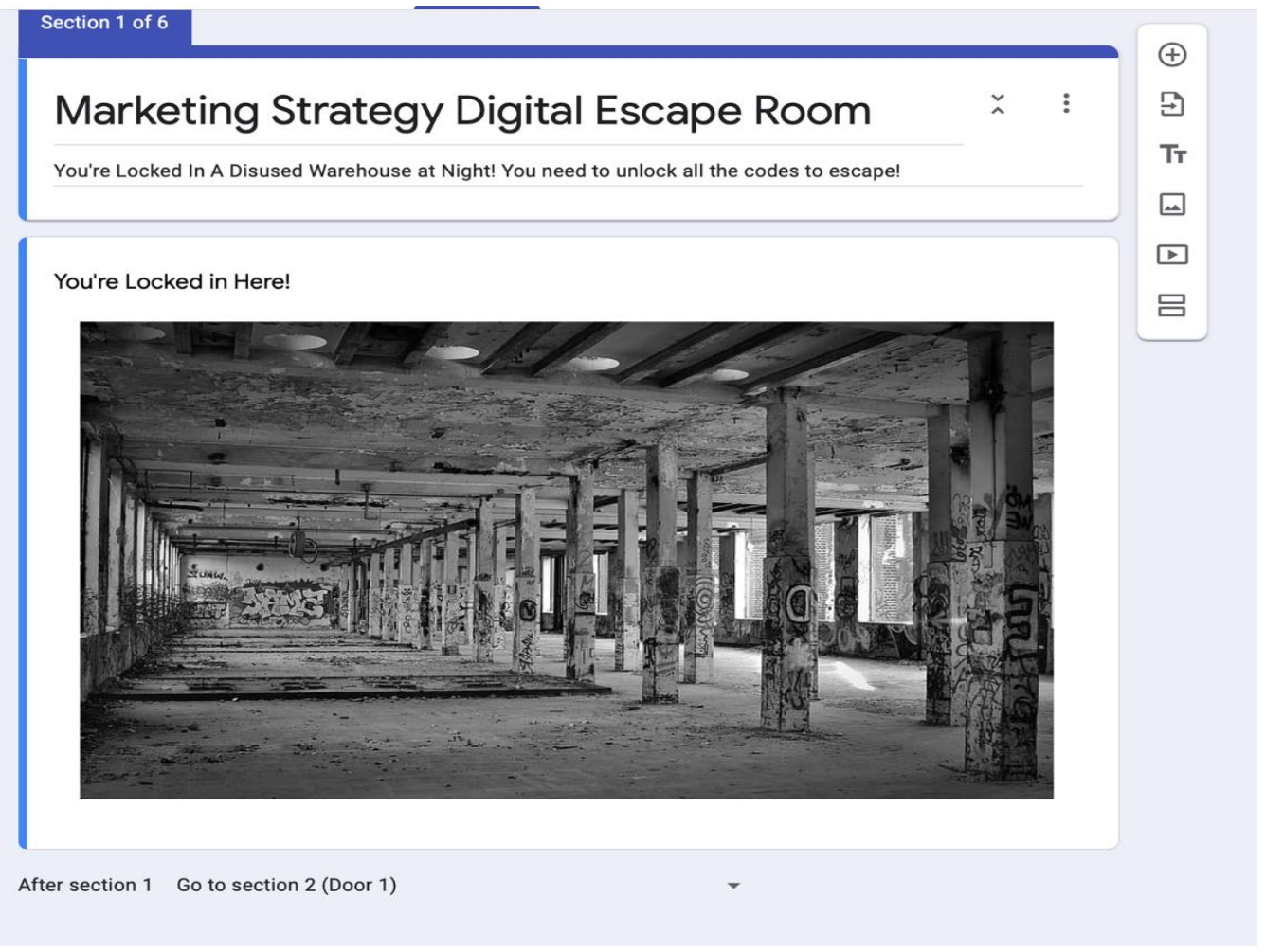




\section{The recommendations}

This activity worked well as shown here in the online environment for individual work but this could work equally well in a hybrid or face-to-face class. I would have liked to have seen a higher percentage of students participate. This could be achieved by making participation more rewarding by adding a competitive element. Extrinsic motivational factors and achievement based rewards, such as praise, promotion, recognition, competition, time constraints, game grading, 'victory signs', leader boards, and bonus points, go a long way in stimulating users to participate. Rewards should not be the sole reason for completing the game process, but they can serve as a supplemental incentive for students. Winning is an intrinsic motivation for learning (Mullen and Tallent-Runnels, 2006). Prizes could therefore be awarded to students who escape first under timed conditions.

Looking ahead, I plan to keep the escape room activity embedded in the course to encourage asynchronous participation. I will however improve the design by adding more images and more of a storytelling narrative throughout to make it more enticing. Since very few students asked for clues and therefore dropped out of the activity, I plan to incorporate clues in to the activity itself to save students from having to email me.

Besides its effectiveness in stimulating motivation and engagement, the digital escape room also has the ability to foster valuable skills such as teamwork, leadership skills, creative thinking, and communication (López-Pernas et al., 2019).

It can easily be adapted as a collaborative exercise to build team-working skills either online or offline and to develop a greater sense of community amongst leaners. Although, I approached the design in a simple manner given time and resource constraints, this basic approach serves as a useful starting point. By adding more images, videos and narrative, the exercise can be made more engaging. Although time consuming, digital escape rooms are easy to set up and there are resources available online and instructions on YouTube on how to do this. 


\section{References}

Barata, G., Gama, S., Jorge, J. and Gonçalves, D. (2013) 'Engaging engineering students with gamification', 5th International Conference on Games and Virtual Worlds for Serious Applications (VS-GAMES). Bournemouth University, Poole 11-13 September. IEEE, pp.1-8. https://doi.org/10.1109/VS-GAMES.2013.6624228.

Borrego, C., Fernández, C., Blanes, I. and Robles, S. (2017) 'Room escape at class: escape games activities to facilitate the motivation and learning in computer science', JOTSE, 7(2), pp.162-171. https://doi.org/10.3926/jotse.247.

Brophy, J. E. (2013). Motivating students to learn. New York: Routledge.

Buckley, P. and Doyle, E. (2016) 'Gamification and student motivation', Interactive learning environments, 24(6), pp.1162-1175.

https://doi.org/10.1080/10494820.2014.964263.

Chen, K. C. and Jang, S. J. (2010) 'Motivation in online learning: testing a model of selfdetermination theory', Computers in Human Behavior, 26(4), pp.741-752. https://doi.org/10.1016/j.chb.2010.01.011.

Coller, B. D. and Shernoff, D. J. (2009) 'Video game-based education in mechanical engineering: a look at student engagement', International Journal of Engineering Education, 25(2), pp.308.

Dichev, C. and Dicheva, D. (2017) 'Gamifying education: what is known, what is believed and what remains uncertain: a critical review', International journal of educational technology in higher education, 14(1), pp.1-36. https://doi.org/10.1186/s41239-0170042-5.

Eccles, J. (1983) 'Expectance, values, and academic behaviors', in Spence, J. T. (ed.) Achievement and achievement motives: psychological and social approaches. San Francisco: Freeman, pp.75-146. 
Fujita-Starck, P. J. and Thompson, J. A. (1994) 'The effects of motivation and classroom environment on the satisfaction of non-credit continuing education students', AIR 1994 Annual Forum Paper. Available at: https://eric.ed.gov/?id=ED373646 (Accessed: 8 August 2021).

Kapp, K. M. (2012) The gamification of learning and instruction: game-based methods and strategies for training and education. San Francisco: John Wiley \& Sons.

Lepper, M. R. and Cordova, D. I. (1992) 'A desire to be taught: instructional consequences of intrinsic motivation', Motivation and Emotion, 16(3), pp.187-208. https://doi.org/10.1007/bf00991651.

Lim, D. H. (2004) 'Cross cultural differences in online learning motivation', Educational Media International, 41(2), pp.163-173. https://doi.org/10.1080/09523980410001685784.

López-Pernas, S., Gordillo, A., Barra, E. and Quemada, J. (2019) 'Examining the use of an educational escape room for teaching programming in a higher education setting', IEEE Access, 7, pp.31723-31737. https://doi.org/10.1109/access.2019.2902976.

Makri, A., Vlachopoulos, D. and Martina, R. A. (2021) 'Digital escape rooms as innovative pedagogical tools in education: a systematic literature review', Sustainability, 13(8), pp.45-87. https://doi.org/10.3390/su13084587.

Mullen, G. E. and Tallent-Runnels, M. K. (2006) 'Student outcomes and perceptions of instructors' demands and support in online and traditional classrooms', The Internet and Higher Education, 9(4), pp.257-266. https://doi.org/10.1016/j.iheduc.2006.08.005.

Sankaran, S. R. and Bui, T. (2001) 'Impact of learning strategies and motivation on performance: a study in web-based instruction', Journal of Instructional Psychology, 28(3), p.191. Available at: 
https://www.thefreelibrary.com/Impact+of+Learning+Strategies+and+Motivation+on +Performance\%3A+A+Study...-a079370574 (Accessed: 8 August 2021).

Vallerand, R. J. and Bissonnette, R. (1992) 'Intrinsic, extrinsic, and amotivational styles as predictors of behavior: a prospective study', Journal of Personality, 60(3), pp.599620. https://doi.org/10.1111/j.1467-6494.1992.tb00922.x.

\section{Appendix 1: sample problem set}

Virtual Escape Room Problem Set - Room 1

Undo the first lock in the digital escape room.

Question: What are the four major steps in designing a customer-driven marketing strategy?

Now take the first letter of each step (all caps) and this is the code you need to unlock Lock 1 of the escape room.

Answer: STDP

Undo the second lock in the digital escape room.

Question: What is the missing word here? This whole word (all caps) will unlock the second lock.

'Brand equity is a set of brand and liabilities linked to a brand name and symbol, which add to or subtract from the value provided by a product or service.'

\section{Answer: ASSETS}

Undo the third lock in the digital escape room. 
Question: what are the answers to the following MCQs? Take the letters of the answers to the following MCQs in order (all caps) and this is the code you need to unlock the third lock.

1) Which of the following is a significant challenge presented by the product life cycle?
A) increased expenses
B) increased competition
C) new product development
D) evaluation of results

2) Which of the following is a common reason for new product failure?
A) incorrect estimation of the market size
B) low product development costs
C) ineffective social marketing campaigns
D) low selling prices of products

3) Which of the following is true with regard to price?
A) Historically, price has had the least perceptible impact on buyer choice.
B) Price is the least flexible element in the marketing mix.
C) Unlike product features and channel commitments, prices cannot be changed quickly.
D) Price is the sum of all the values that customers give up to gain the benefits of having a product.

4) The sets of firms that supply companies with the raw materials, components, parts, information, finances, and expertise needed to create products or services are known as
A) retailers
B) upstream partners
C) distributors
D) downstream partners

Answer: CADB

Undo the fourth lock in the digital escape room. 
What are the four marketing concepts? Take the first letter of each (five letters in total as one concept is two words) and this is the code you need to unlock the fourth lock. Get this right, and you'll get to the next room!

Hint:

Sustainable marketing calls for meeting the present needs of consumers and businesses while also preserving or enhancing the ability of future generations to meet their needs. The marketing concept recognizes that organizations thrive from day to day by determining the current needs and wants of target group customers and fulfilling those needs and wants more effectively and efficiently than the competition. The societal marketing concept considers the future welfare of consumers while the strategic planning concept considers future company needs.

Answer: SMSSP

\section{Author details}

Lucy Gill -Simmen is a Senior Lecturer in Marketing. She is a Senior Fellow of the Higher Education Academy and is Director of Education Strategy at Royal Holloway, University of London. 